\title{
ERCC1 as a biomarker for bladder cancer patients likely to benefit from adjuvant chemotherapy
}

Jong-Mu Sun ${ }^{1 \dagger}$, Ji-Youn Sung ${ }^{2 \dagger}$, Se Hoon Park', Ghee Young Kwon², Byong Chang Jeong ${ }^{3}$, Seong II Seo ${ }^{3}$, Seong Soo Jeon ${ }^{3}$, Hyun Moo Lee ${ }^{3}$, Jisuk Jo ${ }^{4}$, Han Yong Choi ${ }^{3}$ and Ho Yeong Lim ${ }^{1^{*}}$

\begin{abstract}
Background: The role of adjuvant chemotherapy and the value of molecular biomarkers in bladder cancer have not been determined. We aimed to assess the predictive and prognostic values of excision repair crosscomplementation 1 (ERCC1) in identifying appropriate patients who may potentially benefit from adjuvant chemotherapy for bladder cancer.

Methods: A retrospective analysis was performed on 93 patients with completely resected transitional cell carcinoma of the bladder. ERCC1 expression was assessed by immunohistochemistry. ERCC1 expression was analyzed in 57 patients treated with adjuvant gemcitabine plus cisplatin chemotherapy and 36 who were not treated.

Results: Among 93 patients, ERCC1 expression was positive in 54 (58.1\%) and negative in 39 (41.9\%). ERCC1 positivity was significantly associated with longer survival (adjusted hazard ratio for death, $0.12,95 \%$ confidence interval [Cl] 0.014-0.99; $P=0.049$ ) in the group without adjuvant chemotherapy while ERCC1 positivity was associated with shorter survival among patients who have received adjuvant chemotherapy (adjusted hazard ratio for death, 2.64; 95\% Cl 1.01-6.85; $P=0.047$ ). Therefore, clinical benefit from adjuvant chemotherapy was associated with ERCC1 negativity as measured by overall survival (test for interaction, $\mathrm{P}=0.034$ ) and by disease-free survival (test for interaction, $\mathrm{P}=0.20$ ).

Conclusions: Among patients with completely resected transitional cell carcinoma of the bladder, those with ERCC1-negative tumors seemed to benefit more from adjuvant gemcitabine plus cisplatin chemotherapy than those with ERCC1-positive tumors. Future prospective, randomized studies are warranted to confirm our findings.
\end{abstract}

\section{Background}

Many patients with locally advanced bladder cancer relapse and subsequently die of their disease, even after potentially curative surgery, because of occult micrometastases present at diagnosis. Perioperative chemotherapy has been investigated for patients who undergo cystectomy for locally advanced transitional cell carcinoma of the bladder, and clinical benefit from neoadjuvant cisplatin-based chemotherapy has been demonstrated in several randomized trials [1-3].

\footnotetext{
* Correspondence: hoy.lim@samsung.com

${ }^{\dagger}$ Equal contributors

${ }^{1}$ Division of Hematology-Oncology, Department of Medicine, Samsung Medical Center, Sungkyunkwan University School of Medicine, Seoul, South Korea

Full list of author information is available at the end of the article
}

Although two meta-analyses showed favorable results for adjuvant chemotherapy for bladder cancer $[4,5]$, no randomized trial has demonstrated the efficacy of adjuvant chemotherapy for overall survival because of small sample size, or early stoppage of patient entry [6-9]. In practice, however, many physicians administer adjuvant chemotherapy despite its weak evidence [10,11]. Further research investigating the effect of adjuvant chemotherapy on bladder cancer survival is of high importance considering its current practice .

Cisplatin is the most important adjuvant chemotherapy agent for bladder cancer and is usually administered with gemcitabine. Its cytotoxicity is attributed to the formation of DNA adducts, which cause inter- and intrastrand cross-linking that inhibits DNA replication. Cisplatininduced DNA adducts are removed by the nucleotideexcision repair pathway, and the excision repair

\section{Biomed Central}


crosscomplementation 1 (ERCC1) protein is rate-limiting in the nucleotide excision repair pathway. Its increased expression is associated with resistance to cisplatin-based chemotherapy in various tumor types [12-17].

In addition to its predictive role for cisplatin-based chemotherapy, ERCC1 has significant prognostic value because high ERCC1 expression is associated with longer survival in patients who do not receive chemotherapy after complete resection for non-small cell lung cancer $[15,18]$. ERCC1 has also been supported by studies that demonstrate cancers with extensive geno- mic alterations have more malignant phenotype and increased growth rates, and ERCC1 may be representative of the intrinsic DNA damage-repair ability of the cell $[18,19]$.

In this study, we sought to determine whether ERCC1 protein expression is an important factor in predicting the clinical outcome of completely resected bladder cancer. To assess the predictive and prognostic value of ERCC1 and to define the subgroup of patients who are most likely to benefit from adjuvant chemotherapy, patients classified by history of adjuvant chemotherapy were analyzed.

\section{Methods}

\section{Patients and treatment}

The initial study population comprised of 137 patients treated with radical cystectomy and bilateral pelvic lymphadenectomy as definitive treatment for clinically localized urothelial cancer of the bladder between January 2004 and December 2010 at Samsung Medical Center (Seoul, Korea). Of these, 93 patients were included in the analysis after excluding 12 patients who had not been completely resected, eight who received neoadjuvant chemotherapy, 17 patients whose tumors are $\mathrm{pTa} / \mathrm{pT} 1$ with negative node, and seven who did not have available tissue for immunohistochemical analysis for ERCC1. None received pelvic irradiation after complete resection or had documented residual disease before receiving adjuvant chemotherapy. All specimens included in this study were transitional cell carcinoma.

Adjuvant chemotherapy included a maximum of four cycles of gemcitabine (1250 mg/m $\mathrm{m}^{2}$ on days 1 and 8) plus cisplatin $\left(70 \mathrm{mg} / \mathrm{m}^{2}\right.$ on day 1$)$ every 21 days. Adjuvant chemotherapy was given to patients with pathologically advanced bladder cancer (T3/4 or positive node) between three to eight weeks after complete resection. The decision to treat with adjuvant chemotherapy was made after a full discussion with patients, and was based on pathologic tumor stage and patient age or performance status.

Clinicopathologic characteristics including age at operation, sex, histology, tumor stage, and tumor grade were extracted from medical records. The study was approved by the Institutional Review Board of Samsung Medical Center.

\section{Immunohistochemistry for ERCC1}

To accurately assess the median value of ERCC1 in urothelial cancer, we also included additional 149 patients with transitional cell carcinoma originating from completely resected ureter or renal pelvis between January 2004 and December 2010. This resulted in 242 patients for ERCC1 expression analysis.

Representative paraffin blocks, selected by primary evaluation of haematoxylin-eosin stained slides, were chosen for tissue microarray (TMA) preparation. Four tissue cores were collected from each tumor with a sample punch $(0.6 \mathrm{~mm}$ in diameter) and placed in four new recipient paraffin blocks. Each recipient block contained

Table 1 Characteristics of 93 patients with urothelia bladder carcinoma treated with radical cystecomy and bilateral lymphadenectomy

\begin{tabular}{|c|c|}
\hline Characteristic & No. (\%) \\
\hline Total & $93(100.0)$ \\
\hline Median age (range) & $63(34-79)$ \\
\hline \multicolumn{2}{|l|}{ Sex } \\
\hline Men & 79 (84.9\%) \\
\hline Women & $14(15.1 \%)$ \\
\hline \multicolumn{2}{|l|}{ Pathological T stage } \\
\hline $\mathrm{T} 1^{*}$ & $4(4.3 \%)$ \\
\hline $\mathrm{T} 2$ & $15(16.1 \%)$ \\
\hline T3 & $52(55.9 \%)$ \\
\hline T4 & $22(23.7 \%)$ \\
\hline \multicolumn{2}{|l|}{ Pathological N stage } \\
\hline Node negative & $61(65.6 \%)$ \\
\hline Node positive & $32(34.4 \%)$ \\
\hline \multicolumn{2}{|l|}{ Histologic type } \\
\hline Squamous differentiation & $11(11.8 \%)$ \\
\hline Other types & $82(88.2 \%)$ \\
\hline \multicolumn{2}{|l|}{ Pathological grade† } \\
\hline G2 & $10(10.8 \%)$ \\
\hline G3 & $83(89.2 \%)$ \\
\hline \multicolumn{2}{|l|}{ ERCC1 expression } \\
\hline Positive & $54(58.1 \%)$ \\
\hline Negative & $39(41.9 \%)$ \\
\hline \multicolumn{2}{|c|}{ Adjuvant chemotherapy (gemcitabine plus cisplatin) } \\
\hline Yes & $57(61.3 \%)$ \\
\hline 4 cycles & $24(25.8 \%)$ \\
\hline 3 cycles & $28(30.1 \%)$ \\
\hline 2 cycles & $4(4.3 \%)$ \\
\hline 1 cycle & $1(1.1 \%)$ \\
\hline No & $36(38.7 \%)$ \\
\hline
\end{tabular}

*all patients have metastatic lymph nodes. † 1973 WHO grading. 


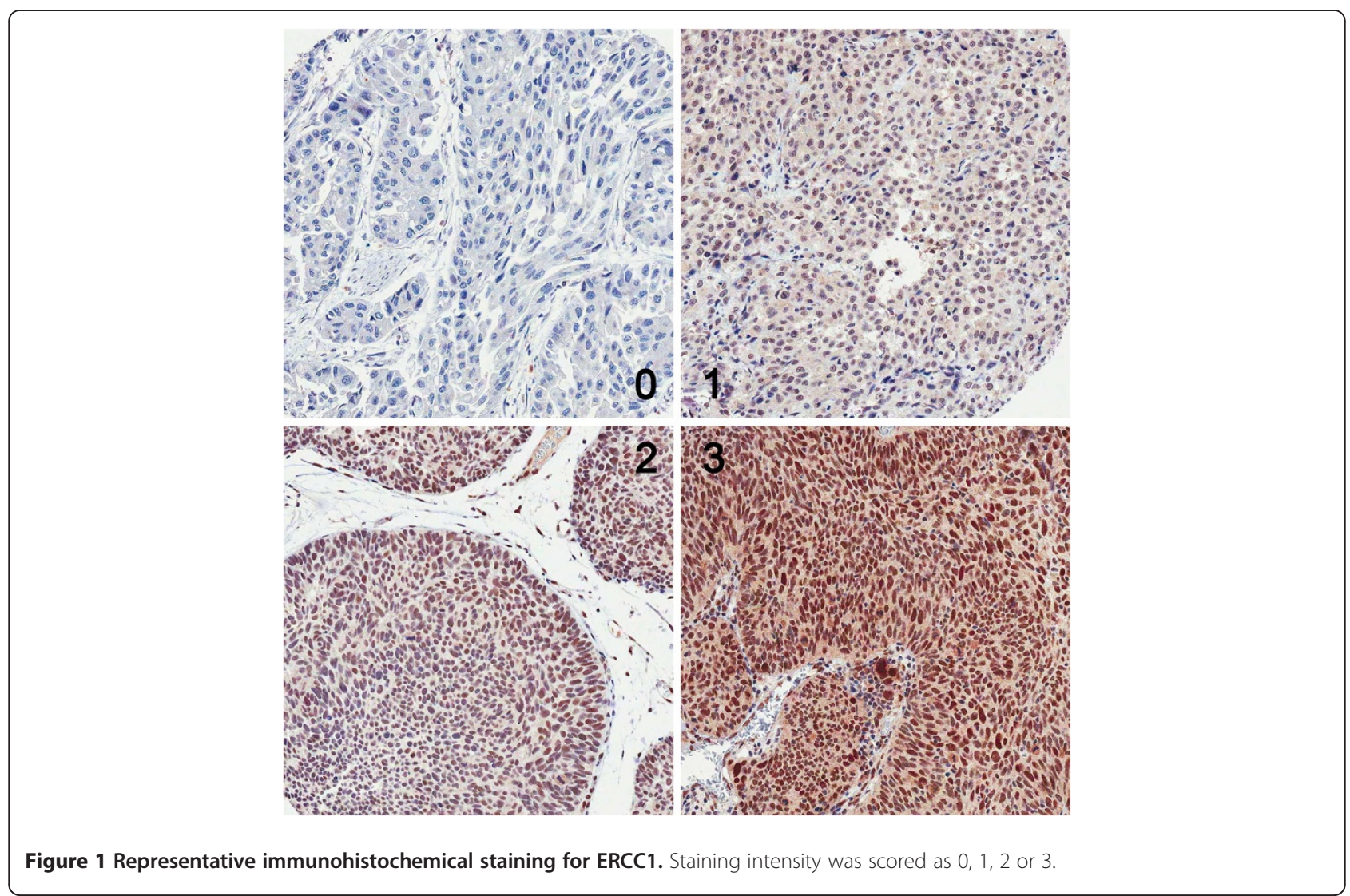

100 individual sample tissue cores and three tonsil tissue samples as controls and was prepared with agar in our lab.

Immunohistochemistry was carried out on 4- $\mu$ m tissue sections using the Bond Polymer Intense Detection System (VisionBioSystems, VIC, Australia) according to the manufacturer's instructions, with minor modifications. In brief, formalin-fixed, paraffin-embedded tissue sections were deparaffinized with Bond Dewax Solution (VisionBioSystems) and an antigen-retrieval procedure performed using Bond ER Solution (VisionBioSystems) for 20 minutes at $100^{\circ} \mathrm{C}$. Endogenous peroxidase was quenched by incubation with hydrogen peroxide for 7 minutes. Sections were incubated in a Bond-max automatic slide stainer (VisionBioSystems) for 15 minutes at ambient temperature with primary mouse monoclonal antibody against ERCC1 (1:150; 8 F1, Gene Tex, Irvine, CA, USA) labeled using a biotin-free polymeric horseradish peroxidase (HRP)-linker antibody conjugate system. Bound peroxidase was visualized using a solution of diaminobenzidine as the chromogen, and nuclei were counterstained with Mayer's hematoxylin. Stromal cells around the tumor portion were used as an internal positive control.

ERCC1 immunohistochemical staining was assessed by two blinded investigators (J Sung and GY Kwon) who reviewed the cases simultaneously at a multihead viewing microscope. Nuclear staining was considered positive.
Staining intensity was defined as follows: 0 , no staining; 1 , weak; 2, moderate; 3, strong. Quantification of positivity (0\%-100\%) was based on an estimate of the percentage of stained tumor cells in the tissue microarray core. The final histochemical score (H-score) was obtained by multiplying staining intensity by percent positivity, giving $\mathrm{H}$-scores ranging from 0 to 300 . An $\mathrm{H}$-score higher than the median was considered positive.

\section{Statistical analysis}

The primary endpoint of overall survival was calculated from the day of operation to the date of death or final follow-up. Disease-free survival was defined from the day of operation to documented diseased recurrence or death from any cause. Patients without recurrent disease at the time of analysis were censored for the final follow-up.

The relationships between ERCC1 expression and clinicopathologic factors were analyzed using a Chi-square test. Survival curves were generated using the Kaplan-Meier method, and the log-rank test was used to compare survival curves according to clinicopathological characteristics including ERCC1 expression. A multivariate regression analysis was carried out using Cox's regression analysis. A Cox proportional hazards regression model was used to test for interaction between ERCC1 expression and adjuvant chemotherapy. All analyses were performed with the 
use of SPSS 19.0 (SPSS Inc, Chicago, IL, USA) and SAS 9.1 (SAS Institute Inc, Cary, NC, USA).

\section{Results}

\section{Patient characteristics}

Table 1 lists baseline patient characteristics. The median patient age was 63 years (range, 34-79), and 79 patients (84.9\%) had advanced disease (pathologic T3/4 or positive node). Eleven patients had transitional cell carcinoma with squamous differentiation. Of 93 patients who entered the study, 57 (61.3\%) were treated with adjuvant chemotherapy and all had advanced disease. Among 36 patients without adjuvant chemotherapy, 22 (61.1\%) had advanced disease and did not receive adjuvant chemotherapy because of old age, poor performance, patient refusal, or other causes.

\section{Assessment of ERCC1 expression}

Figure 1 shows that ERCC1 was localized to the nucleus. The median $\mathrm{H}$-score was 50 (range, $0-300$ ). Tumors with an $\mathrm{H}$-score $>50$ were deemed ERCC1 positive. Of 93 bladder tumors, 54 (58.1\%) were ERCC1 positive and 39 (41.9\%) were ERCC1 negative. No significant differences were found in the clinicopathologic parameters between patients with ERCC1-positive and those with ERCC1negative tumors in groups with or without adjuvant chemotherapy or in the total population (Table 2).

\section{Overall survival and ERCC1 expression}

The 5-year overall survival rate was 56.0\% (95\% confidence interval $[\mathrm{CI}], 51.8 \%-60.3 \%)$ for the total study population. According to the Cox model adjusted for the multivariate predictors of survival, ERCC1-positive tumors, compared with ERCC1-negative tumors, had no prognostic value for the entire study population (adjusted hazard ratio [HR] for death, 1.15; 95\% CI, 0.55-2.40; $\mathrm{P}=0.71$ ).

\section{Prognostic value of ERCC1 expression according to adjuvant chemotherapy}

Among patients without adjuvant chemotherapy, the 5year overall survival rate was higher in ERCC1-positive tumors than in ERCC1-negative tumors (84.0\% vs. 49.2\%; $\mathrm{P}=0.083$ ) (Table 3, Figure 2a). Other clinical characteristics such as male, positive lymph node, and transitional cell carcinoma with squamous differentiation had poor prognostic values by univariate analysis. Results from multivariate analysis indicate ERCC1 positivity (adjusted HR for death, 0.12; 95\% CI 0.014-0.99; $\mathrm{P}=0.049$ ), negative lymph node (adjusted HR for death, 0.066; 95\% CI 0.005$0.82 ; \mathrm{P}=0.035$ ), and histologic types other than squamous cell differentiation (adjusted HR for death, 0.033 ; 95\% CI 0.002-0.62; $\mathrm{P}=0.022$ ) were significantly associated with longer survival. Among patients who were treated with adjuvant chemotherapy, the 5-year overall survival rate was

Table 2 Associations between ERCC1 expression and clinical characteristics in groups with or without adjuvant chemotherapy

\begin{tabular}{|c|c|c|c|c|c|c|c|c|c|}
\hline \multirow[t]{2}{*}{ Characteristic } & \multicolumn{3}{|c|}{$\begin{array}{l}\text { Adjuvant chemotherapy } \\
\qquad(n=57)\end{array}$} & \multicolumn{3}{|c|}{$\begin{array}{l}\text { No adjuvant chemotherapy } \\
\qquad(\mathrm{n}=36)\end{array}$} & \multicolumn{3}{|c|}{$\begin{array}{c}\text { Total } \\
(n=93)\end{array}$} \\
\hline & $\begin{array}{l}\text { ERCC1 (+) } \\
(\mathrm{n}=34)\end{array}$ & $\begin{array}{l}\mathrm{ERCC1}(-) \\
(\mathrm{n}=23)\end{array}$ & $P$ & $\begin{array}{c}\text { ERCC1 }(+) \\
(n=20)\end{array}$ & $\begin{array}{l}\text { ERCC1 (-) } \\
(n=16)\end{array}$ & $P$ & $\begin{array}{l}\mathrm{ERCC1}(+) \\
(\mathrm{n}=54)\end{array}$ & $\begin{array}{l}\text { ERCC1 (-) } \\
(\mathrm{n}=39)\end{array}$ & $P$ \\
\hline Sex & & & 0.49 & & & 0.19 & & & 0.21 \\
\hline Men & $29(85.3 \%)$ & $18(78.3 \%)$ & & 19 (95.0\%) & $13(81.3 \%)$ & & $48(88.9 \%)$ & $31(79.5 \%)$ & \\
\hline Women & $5(14.7 \%)$ & $5(21.7 \%)$ & & $1(5.0 \%)$ & $3(18.8 \%)$ & & $6(11.1 \%)$ & $8(20.5 \%)$ & \\
\hline Age at operation & & & 0.35 & & & 0.24 & & & 0.92 \\
\hline$\geq 65$ years & $8(23.5 \%)$ & $8(34.8 \%)$ & & $15(75.0 \%)$ & $9(56.3 \%)$ & & $23(42.6 \%)$ & $17(43.6 \%)$ & \\
\hline$<65$ years & $26(76.5 \%)$ & $15(65.2 \%)$ & & $5(25.0 \%)$ & $7(43.8 \%)$ & & $31(57.4 \%)$ & $22(56.4 \%)$ & \\
\hline T stage & & & 0.68 & & & 0.65 & & & 0.99 \\
\hline T1-T2 & $2(5.9 \%)$ & $2(8.7 \%)$ & & $9(45.0 \%)$ & $6(37.5 \%)$ & & $11(20.4 \%)$ & $8(20.5 \%)$ & \\
\hline T3-T4 & $32(94.1 \%)$ & $21(91.3 \%)$ & & $11(55.0 \%)$ & $10(62.5 \%)$ & & $43(79.6 \%)$ & $31(79.5 \%)$ & \\
\hline$N$ stage & & & 0.48 & & & 0.58 & & & 0.13 \\
\hline Node negative & $16(47.1 \%)$ & $13(56.5 \%)$ & & $16(80.0 \%)$ & $16(100 \%)$ & & $32(59.3 \%)$ & $29(74.4 \%)$ & \\
\hline Node positive & $18(52.9 \%)$ & $10(43.5 \%)$ & & $4(20.0 \%)$ & $0(0 \%)$ & & $22(40.7 \%)$ & $10(25.6 \%)$ & \\
\hline Histologic type & & & 0.64 & & & 0.87 & & & 0.69 \\
\hline Squamous differentiation & $6(17.6 \%)$ & $3(13.0 \%)$ & & $1(5.0 \%)$ & $1(6.3 \%)$ & & $7(13.0 \%)$ & $4(10.3 \%)$ & \\
\hline Other types & $28(82.4 \%)$ & $20(87.0 \%)$ & & 19 (95.0\%) & 15 (93.8\%) & & 47 (87.0\%) & $35(89.7 \%)$ & \\
\hline Pathologic grade* & & & 0.74 & & & 0.69 & & & 0.22 \\
\hline Grade 2 & $2(5.9 \%)$ & $5(21.7 \%)$ & & $2(10.0 \%)$ & $1(6.3 \%)$ & & $64(7.4 \%)$ & $(15.4 \%)$ & \\
\hline Grade 3 & 32 (94.1\%) & 18 (78.3\%) & & 18 (90.0\%) & 15 (93.8\%) & & 50 (92.6\%) & $33(84.6 \%)$ & \\
\hline
\end{tabular}

*1973 WHO grading. 
Table 3 Overall survival in groups without or with adjuvant chemotherapy

\begin{tabular}{|c|c|c|c|c|c|c|}
\hline & \multicolumn{3}{|c|}{ No adjuvant chemotherapy group } & \multicolumn{3}{|c|}{ Adjuvant chemotherapy group } \\
\hline & No. (\%) & 5-Y OS rate (\%) & $P$ & No. (\%) & $5-Y$ OS rate $(\%)$ & $P$ \\
\hline All patients & $36(100)$ & 68.3 & & $57(100)$ & 52.3 & \\
\hline ERCC1 status & & & 0.083 & & & 0.074 \\
\hline Positive & $20(55.6)$ & 84.0 & & $34(59.6)$ & 41.6 & \\
\hline Negative & $16(44.4)$ & 49.2 & & $23(40.4)$ & 71.8 & \\
\hline Sex & & & 0.080 & & & 0.14 \\
\hline Male & $32(88.9)$ & 70.6 & & $47(82.5)$ & 46.2 & \\
\hline Female & $4(11.1)$ & 50.0 & & $10(17.5)$ & 77.8 & \\
\hline Age at operation & & & 0.40 & & & 0.99 \\
\hline$\geq 65$ years & $24(66.7)$ & 70.0 & & $16(28.1)$ & 60.3 & \\
\hline$<65$ years & $12(33.3)$ & 61.1 & & $41(71.9)$ & 51.2 & \\
\hline T stage & & & 0.21 & & & 0.57 \\
\hline T1-T2 & $15(41.7)$ & 83.6 & & $4(7.0)$ & 50.0 & \\
\hline T3-T4 & $21(58.3)$ & 59.2 & & $53(93.0)$ & 52.9 & \\
\hline N stage & & & 0.10 & & & 0.73 \\
\hline No & $32(88.9)$ & 70.9 & & $29(50.9)$ & 47.7 & \\
\hline N1-3 & $4(11.1)$ & 50.0 & & $28(49.1)$ & 59.1 & \\
\hline Histologic type & & & 0.088 & & & 0.21 \\
\hline Squamous differentiation & $2(5.6)$ & 50.0 & & $9(15.8)$ & 77.8 & \\
\hline Other types & $34(94.4)$ & 69.8 & & $48(84.2)$ & 46.8 & \\
\hline Pathologic Grade* & & & 0.35 & & & 0.47 \\
\hline G2 & $3(8.3)$ & 100.0 & & $7(12.3)$ & 71.4 & \\
\hline G3 & $33(91.7)$ & 65.7 & & $50(87.7)$ & 50.2 & \\
\hline
\end{tabular}

*1973 WHO grading.

41.6\% for those with ERCC1-positive tumors and 71.8\% for those with ERCC1-negative tumors $(\mathrm{P}=0.074)$ (Table 3, Figure 2b). Multivariate analysis showed that only ERCC1 positivity was significantly associated with shorter survival in the group with adjuvant chemotherapy (adjusted HR for death, 2.64; 95\% CI 1.01-6.85; $\mathrm{P}=0.047)$. Overall, the interaction term between ERCC1 expression and adjuvant chemotherapy was significant for overall survival $(P=0.034)$.

\section{Disease-free survival, ERCC1 expression, and adjuvant chemotherapy}

The 2-year disease-free survival rates for ERCC1-positive and ERCC1-negative tumors were $64.6 \%$ and $44.2 \%$ $(\mathrm{P}=0.28)$ in the group without adjuvant chemotherapy and $46.5 \%$ and $64.5 \%(P=0.19)$ in the group with adjuvant chemotherapy, respectively (Figure 3). The interaction term between ERCC1 expression and adjuvant chemotherapy showed borderline significance for disease-free survival $(\mathrm{P}=0.20)$.

\section{Discussion}

In our study, ERCC1 expression provided both prognostic and predictive information in patients with completely resected bladder cancer. Among patients with transitional cell carcinoma of the bladder treated with cystectomy, high tumoral expression of ERCC1 correlated with longer survival in patients without adjuvant chemotherapy and was associated with shorter survival in those with adjuvant chemotherapy. A statistically significant interaction between ERCC1 expression and adjuvant chemotherapy indicated potential benefits of adjuvant chemotherapy in patients with ERCC1-negative tumors.

To date, the role of adjuvant chemotherapy for bladder cancer has been controversial, with no Level 1 evidence supporting adjuvant chemotherapy. In fact, the available data have not demonstrated a clear benefit of adjuvant chemotherapy. Despite mounting evidence favoring neoadjuvant chemotherapy [1-3], physicians are reluctant to adopt its practice as evidenced by only $1.2 \%$ of patients with stage III bladder cancer receiving neoadjuvant chemotherapy [10]. Nonetheless, $10.4 \%$ of patients from the same cohort received adjuvant chemotherapy, implying a preference for adjuvant chemotherapy over neoadjuvant chemotherapy despite a paucity of evidence $[10,11]$. Such ubiquitous practice might be attributed to two beliefs: that adjuvant chemotherapy could be given 


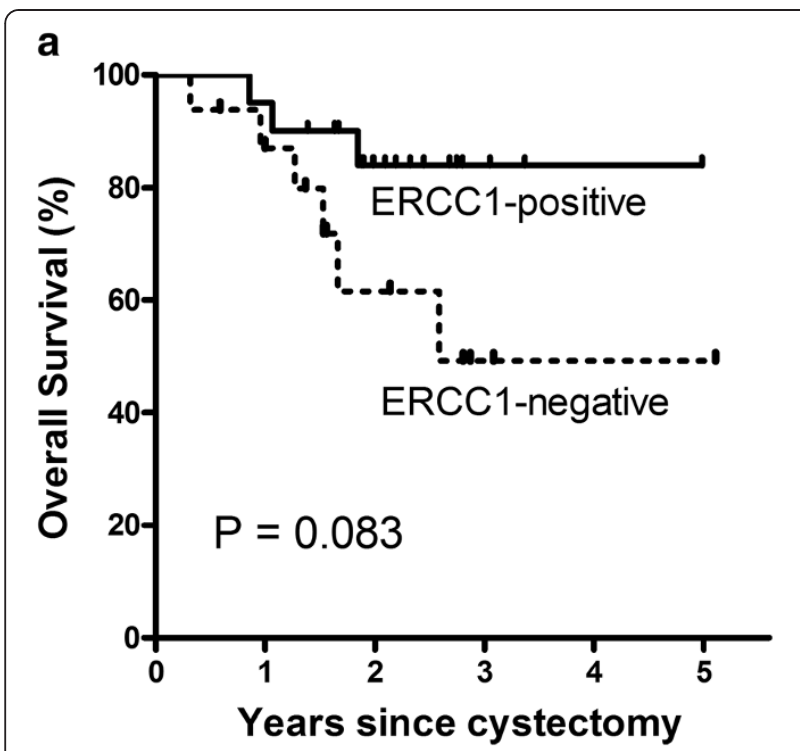

b

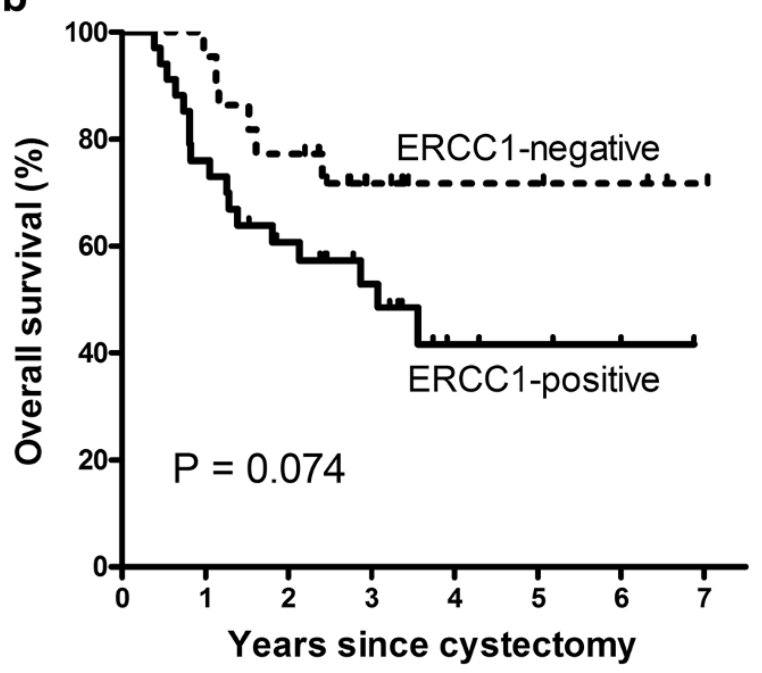

Figure 2 Overall survival. Without adjuvant chemotherapy (a), with adjuvant chemotherapy $(\mathbf{b})$ (interaction $\mathrm{P}=0.034$ ).

to patients under the most accurate pathologic staging, thereby preventing low-risk patients from unnecessary cytotoxicity; and that up-front surgery increases the chances of curing patients with drug-resistant diseases. In order to strengthen evidence-based practice for adjuvant chemotherapy, further research including rigorous study designs and methodologies are warranted.

A significant strength of this study was the appropriate selection of patients who could potentially benefit from adjuvant chemotherapy based on ERCC1 expression. The target populations in previous adjuvant trials were heterogeneous, ranging from T1-T2 disease to node positive disease, and defined only by pathologic stage. A recent prospective study used p53 expression as a molecular marker for selecting a target population for adjuvant chemotherapy [8].
Patients whose tumors were p53-positive were randomly assigned to adjuvant chemotherapy or to observation, and those with p53-negative tumors were all assigned to observation. Although this trial failed to demonstrate the prognostic and predictive value of p53 due to a high patient refusal rate or lower than expected event rate, the attempt to use a molecular marker in adjuvant chemotherapy is noteworthy. Further molecularly targeted adjuvant chemotherapy should be investigated.

ERCC1 is a component of the nucleotide excision repair pathway, which is essential for the repair of DNA adducts induced by cisplatin-based therapy. Several studies have shown that high ERCC1 expression is a good prognostic
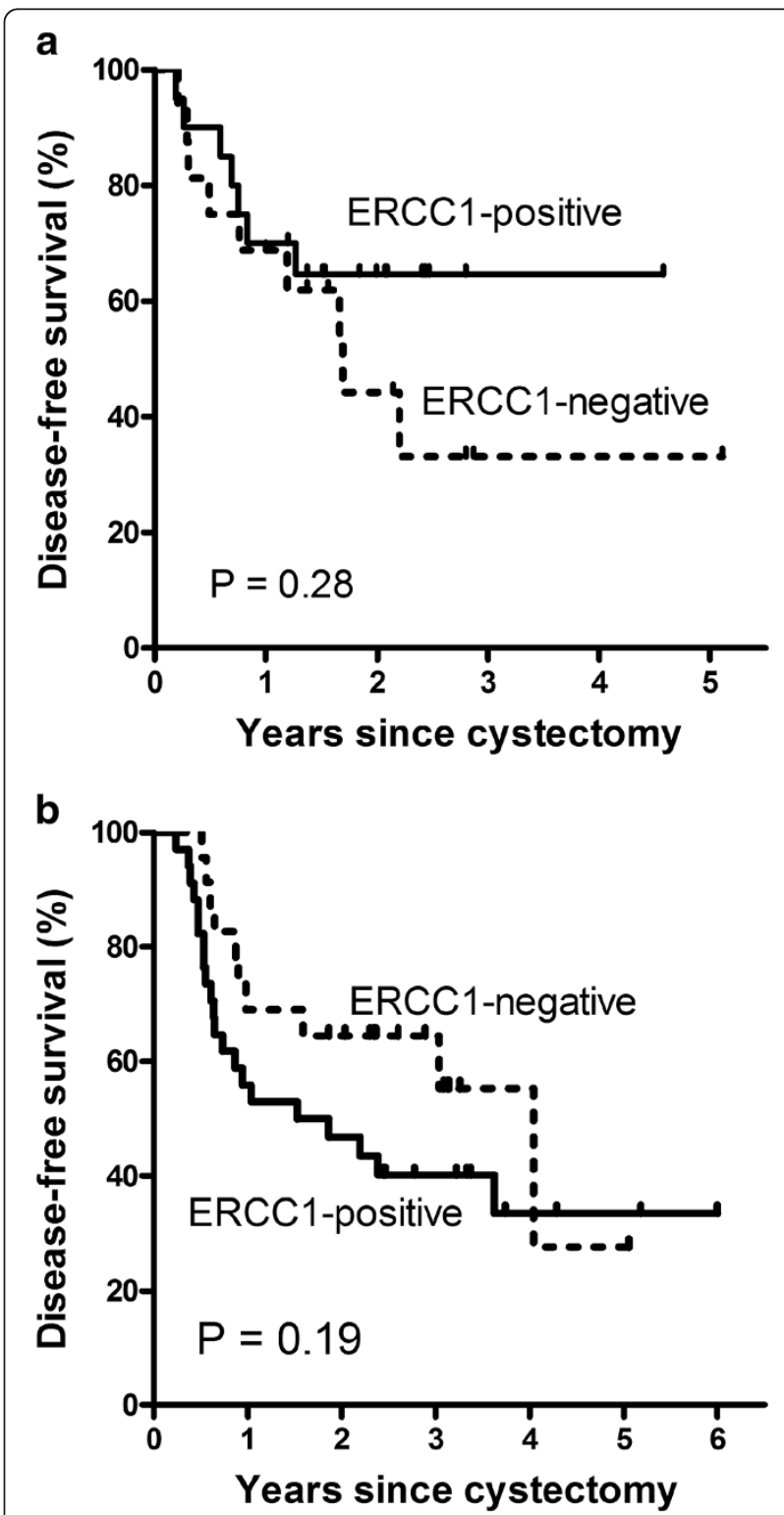

Figure 3 Disease-free survival. Without adjuvant chemotherapy (a), with adjuvant chemotherapy (b) (interaction $P=0.20$ ). 
factor in patients without cisplatin-based chemotherapy and also a predictor for poor clinical outcome in patients with cisplatin-based chemotherapy for various tumor types $[12,14,15,18]$. ERCC1 was also previously evaluated in metastatic bladder cancer, and high ERCC1 mRNA or protein expression correlated with poor prognosis in patients treated with cisplatin-based chemotherapy [20-22]. In muscleinvasive bladder cancer, cisplatin-based chemoradiation therapy showed better efficacy for ERCC1-negative tumors than ERCC1-positive tumors [23]. Hoffmann et al. demonstrated that high ERCC1 gene expressions were associated with inferior progression-free survival after cisplatin-based adjuvant chemotherapy for locally advanced bladder cancer [24]. In the present study, the different prognostic values of ERCC1 according to the history of adjuvant gemcitabine plus cisplatin chemotherapy were confirmed in patients with completely resected bladder cancer.

A limitation of our study includes different patient characteristics between two groups with or without adjuvant chemotherapy owing to the retrospective nature of the study. However, such difference and bias which can potentially influence study results were minimized because the value of ERCC1 expression was analyzed independently in each group. In addition, the adjuvant chemotherapy was homogenous with an identical regimen of gemcitabine plus cisplatin.

In summary, we have demonstrated that ERCC1 may potentially be a novel biomarker with clinical predictive and prognostic values in completely resected bladder cancer. Those who have bladder cancer with low ERCC1 expression are more likely to benefit from adjuvant gemcitabine plus cisplatin chemotherapy. Further researches including prospective randomized studies are warranted to confirm our findings.

\section{Conclusions}

ERCC1 expression has a different prognostic nature according to the history of adjuvant chemotherapy: ERCC1-positivity is associated with poorer prognosis in the group with adjuvant chemotherapy while it has better prognosis in those without adjuvant chemotherapy. In bladder cancer, the relevance of ERCC1 expression as a biomarker selecting patients for adjuvant chemotherapy should be confirmed in further prospective studies.

\section{Competing interests}

All authors declare that they have no actual or potential competing interests including any financial, personal or other relationships with other people or companies/organizations that could inappropriately influence this article.

\section{Author details}

${ }^{1}$ Division of Hematology-Oncology, Department of Medicine, Samsung Medical Center, Sungkyunkwan University School of Medicine, Seoul South Korea. ${ }^{2}$ Department of Pathology, Samsung Medical Center, Sungkyunkwan University School of Medicine, Seoul South Korea. ${ }^{3}$ Department of Urology, Samsung Medical Center, Sungkyunkwan University School of Medicine,
Seoul South Korea. ${ }^{4}$ Cancer Research Institute, Research Institute for Future Medicine, Samsung Medical Center, Seoul South Korea.

\section{Authors' contributions}

JS contributed to the design, acquisition of data, analysis of data, and drafting the manuscript. JS and GYK contributed to the conception, pathologic review, and drafted the manuscript. HYL contributed to the conception, design, and provided final approval of the version to be published. JJ contributed to the analysis of data. SHP, BCJ, SIS, SSJ, HML, and HYC contributed to the acquisition of data. All authors read and approved the final manuscript.

Received: 26 November 2011 Accepted: 22 May 2012

Published: 22 May 2012

\section{References}

1. Sherif A, Rintala E, Mestad O, Nilsson J, Holmberg L, Nilsson S, Malmström P-U: Neoadjuvant cisplatin-methotrexate chemotherapy for invasive bladder cancer - nordic cystectomy trial 2. Scand J Urol Nephrol 2002, 36(6):419-425.

2. Grossman HB, Natale RB, Tangen CM, Speights VO, Vogelzang NJ, Trump DL, White RWd, Sarosdy MF, Wood DP, Raghavan D, et al: Neoadjuvant chemotherapy plus cystectomy compared with cystectomy alone for locally advanced bladder cancer. N Eng J Med 2003, 349(9):859-866.

3. Griffiths G, Hall R, Sylvester R, Raghavan D, Parmar MK: International phase III trial assessing neoadjuvant cisplatin, methotrexate, and vinblastine chemotherapy for muscle-invasive bladder cancer: long-term results of the BA06 30894 trial. J Clin Oncol 2011, 29(16):2171-2177.

4. Claire LV: Adjuvant chemotherapy in invasive bladder cancer: a systematic review and meta-analysis of individual patient data: advanced bladder cancer (abc) meta-analysis collaboration. Eur Urol 2005, 48(2):189-201.

5. Ruggeri EM, Giannarelli D, Bria E, Carlini P, Felici A, Nelli F, Gallucci M, Cognetti F, Pollera CF: Adjuvant chemotherapy in muscle-invasive bladder carcinoma. Cancer 2006, 106(4):783-788

6. Cognetti F, Ruggeri EM, Felici A, Gallucci M, Muto G, Pollera CF, Massidda B, Rubagotti A, Giannarelli D, Boccardo F, et al: Adjuvant chemotherapy with cisplatin and gemcitabine versus chemotherapy at relapse in patients with muscle-invasive bladder cancer submitted to radical cystectomy: an Italian, multicenter, randomized phase III trial. Ann Oncol 2012, 23(3):695-700.

7. Paz-Ares L, Solsona E, Esteban E, Gonzalez-Larriba J, Anton A, Hevia M, Guillem V, Rosa F, Bellmunt J: Randomized phase III trial comparing adjuvant paclitaxel/gemcitabine/cisplatin (PGC) to observation in patients with resected invasive bladder cancer: Results of the Spanish Oncology Genitourinary Group (SOGUG) 99/01 study. J Clin Oncol 2010, 28(suppl):7. s (Abstr LBA4518).

8. Stadler WM, Lerner SP, Groshen S, Stein JP, Shi S-R, Raghavan D, Esrig D, Steinberg G, Wood D, Klotz L, et al: Phase III study of molecularly targeted adjuvant therapy in locally advanced urothelial cancer of the bladder based on p53 status. J Clin Oncol 2011, 29(25):3443-3449.

9. Studer UE, Bacchi M, Biedermann C, Jaeger P, Kraft R, Mazzucchelli L, Markwalder R, Senn E, Sonntag RW: Adjuvant cisplatin chemotherapy following cystectomy for bladder cancer: results of a prospective randomized trial. J Urol 1994, 152(1):81-84.

10. David KA, Milowsky MI, Ritchey J, Carroll PR, Nanus DM: Low incidence of perioperative chemotherapy for stage iii bladder cancer 1998 to 2003: a report from the national cancer data base. J Urol 2007, 178(2):451-454

11. Hussain MHA, Wood DP, Bajorin DF, Bochner BH, Dreicer R, Lamm DL, O'Donnell MA, Siefker-Radtke AO, Theodorescu D, Dinney CP: Bladder cancer: narrowing the gap between evidence and practice. J Clin Oncol 2009, 27(34):5680-5684.

12. Lord RV, Brabender J, Gandara D, Alberola V, Camps C, Domine M, Cardenal F, Sanchez JM, Gumerlock PH, Taron M, et al: Low ERCC1 expression correlates with prolonged survival after cisplatin plus gemcitabine chemotherapy in non-small cell lung cancer. Clin Cancer Res 2002, 8 (7):2286-2291.

13. Selvakumaran M, Pisarcik DA, Bao R, Yeung AT, Hamilton TC: Enhanced cisplatin cytotoxicity by disturbing the nucleotide excision repair pathway in ovarian cancer cell lines. Cancer Res 2003, 63(6):1311-1316.

14. Ceppi P, Volante M, Novello S, Rapa I, Danenberg KD, Danenberg PV, Cambieri A, Selvaggi G, Saviozzi S, Calogero R, et al: ERCC1 and RRM1 gene 
expressions but not EGFR are predictive of shorter survival in advanced non-small-cell lung cancer treated with cisplatin and gemcitabine. Ann Oncol 2006, 17(12):1818-1825.

15. Olaussen KA, Dunant A, Fouret $P$, Brambilla E, Andre F, Haddad V, Taranchon E, Filipits M, Pirker R, Popper HH, et al: DNA repair by ERCC1 in non-small-cell lung cancer and cisplatin-based adjuvant chemotherapy. N Engl J Med 2006, 355(10):983-991.

16. Sun J-M, Ahn M-J, Park MJ, Lee H-Y, Ahn JS, Lee S, Kang G, Han J, Son Y-I, Baek C-H, et al: Expression of Excision Repair Cross-Complementation Group 1 as Predictive Marker for Nasopharyngeal Cancer Treated With Concurrent Chemoradiotherapy. Int J Radiat Oncol Biol Phys 2011, 80 (3):655-660.

17. Hwang IG, Ahn MJ, Park BB, Ahn YC, Han J, Lee S, Kim J, Shim YM, Ahn JS, Park K: ERCC1 expression as a prognostic marker in N2(+) nonsmall-cell lung cancer patients treated with platinum-based neoadjuvant concurrent chemoradiotherapy. Cancer 2008, 113(6):1379-1386.

18. Simon GR, Sharma S, Cantor A, Smith P, Bepler G: ERCC1 expression is a predictor of survival in resected patients with non-small cell lung cancer. Chest 2005, 127(3):978-983.

19. Rosell R, Pifarré A, Monzó M, Astudillo J, López-Cabrerizo MP, Calvo R, Moreno I, Sánchez-Céspedes M, Font A, Navas-Palacios JJ: Reduced survival in patients with stage-I non-small-cell lung cancer associated with DNA-replication errors. Int J Cancer 1997, 74(3):330-334.

20. Kim KH, Do I-G, Kim HS, Chang MH, Kim HS, Jun HJ, Uhm J, Yi SY, Lim DH, Ji SH, et al: Excision repair cross-complementation group 1 (ERCC1) expression in advanced urothelial carcinoma patients receiving cisplatin-based chemotherapy. APMIS 2010, 118(12):941-948.

21. Bellmunt J, Paz-Ares L, Cuello M, Cecere F, Albiol S, Guillem V, Gallardo E, Carles J, Mendez P, de la Cruz J, et al: Gene expression of ERCC1 as a novel prognostic marker in advanced bladder cancer patients receiving cisplatin-based chemotherapy. Ann Oncol 2007, 18(3):522-528.

22. Matsumura N, Nakamura $Y$, Kohjimoto $Y$, Inagaki T, Nanpo $Y$, Yasuoka $H$, Ohashi $Y$, Hara I: The prognostic significance of human equilibrative nucleoside transporter 1 expression in patients with metastatic bladder cancer treated with gemcitabine-cisplatin-based combination chemotherapy. BJU Int 2011, 108(2b):E110-E116.

23. Kawashima A, Nakayama M, Kakuta Y, Abe T, Hatano K, Mukai M, Nagahara A, Nakai Y, Oka D, Takayama $\mathrm{H}$, et al: Excision repair cross-complementing group 1 may predict the efficacy of chemoradiation therapy for muscle-invasive bladder cancer. Clin Cancer Res 2011, 17(8):2561-2569.

24. Hoffmann AC, Wild P, Leicht C, Bertz S, Danenberg KD, Danenberg PV, Stohr R, Stockle M, Lehmann J, Schuler M, et al: MDR1 and ERCC1 expression predict outcome of patients with locally advanced bladder cancer receiving adjuvant chemotherapy. Neoplasia 2010, 12(8):628-636.

doi:10.1186/1471-2407-12-187

Cite this article as: Sun et al:: ERCC1 as a biomarker for bladder cancer patients likely to benefit from adjuvant chemotherapy. BMC Cancer 2012 12:187.

\section{Submit your next manuscript to BioMed Central and take full advantage of:}

- Convenient online submission

- Thorough peer review

- No space constraints or color figure charges

- Immediate publication on acceptance

- Inclusion in PubMed, CAS, Scopus and Google Scholar

- Research which is freely available for redistribution 